\title{
Net Neutrality in a hyperlinked Internet economy
}

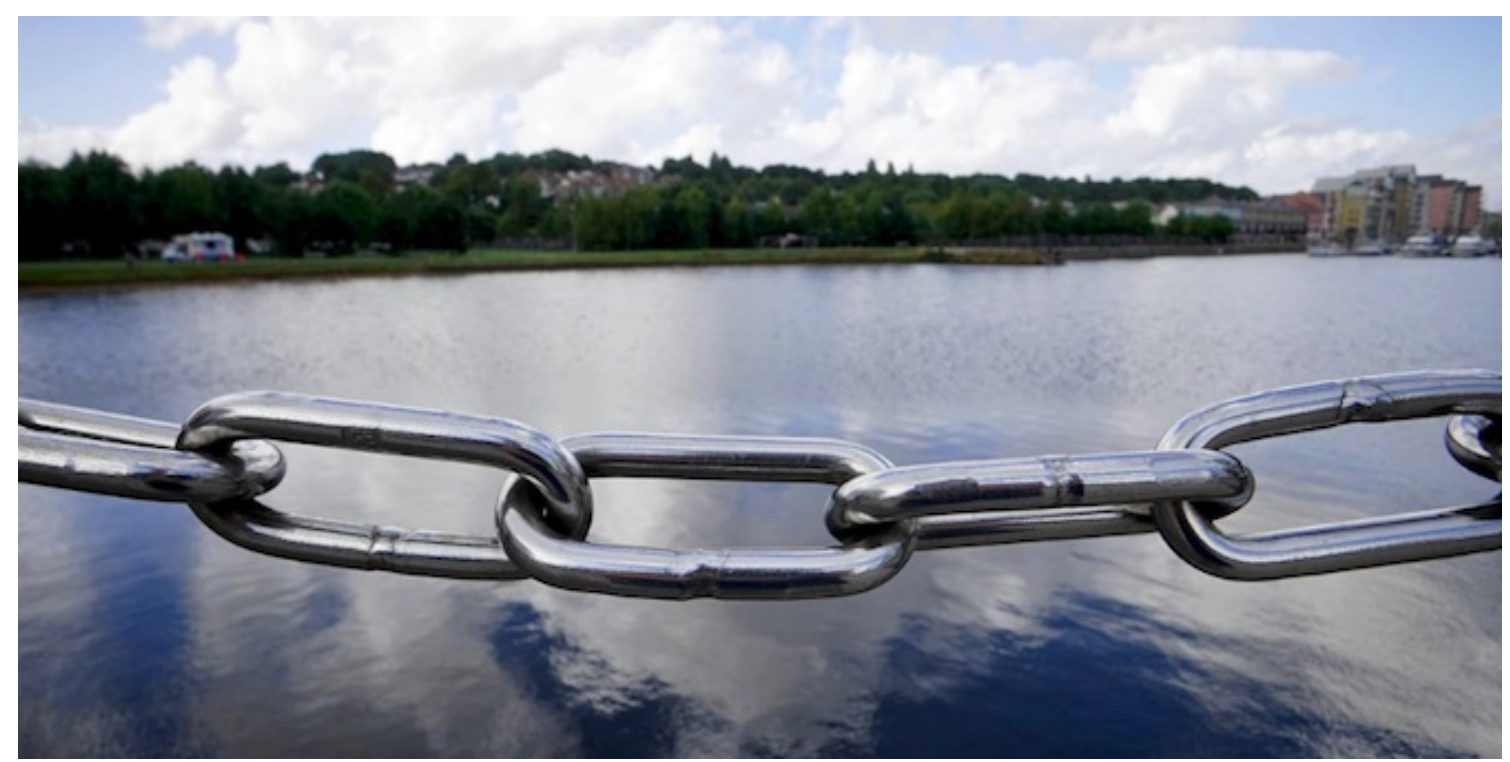

Have you ever realized that the websites and social platforms you use are full of links that lead you to contents, videos or advertisements of other content providers? And that you usually surf from one site to another without typing their URL addresses? No doubt, this is an important feature of the Internet. For instance, direct visits of The New York Times represent only 44 per cent of its total traffic, whereas the rest of traffic is originated through social platforms and search engines. Content Providers (CPs) like receiving this type of indirect visitors because they obtain additional advertisement revenues. A stimulating question is why CPs want to place links to their rivals? For instance, why do social platforms promote users' profiles on other social networks?

In order to answer these questions, we have created a simple economic model in which two CPs compete for visitors, but they can also link each other to enhance their contents. The links give Internet users the opportunity to visit both websites and to obtain more utility; otherwise, they only visit one website. CPs obtain money by embedding advertisements into their contents. Another important element of our model is that CPs have to gain access to the network of an Internet Service Provider (ISP) in order to reach their visitors. Under the Net Neutrality (NN) regime, this access comes for free. Without the NN regulation, CPs have to pay the ISP a termination fee for using its network.

Net Neutrality has been a globally accepted regulation of the Internet service that requires the equal treatment of all data sent and received without differential charges and service quality. This regulation responds to the idea that NN spurs competition among ISPs for product quality, which promotes consumer well-being and social welfare. Net Neutrality is in force in the EU according to the Regulation 2015/2120 in support of a Digital Single Market. However, this view of the Internet market has recently started to change. On December 14, 2017, the US Federal Communications Commission (FCC) effectively reneged on its own 2015 Open Internet Order, which was devised to allow open and fair access to the Internet. As the opponents of this decision have pointed out, ISPs now have the power to block websites, throttle services and censor online content.

Does it mean that, in the US, large ISPs are allowed to negotiate the terms of access to their networks with CPs, affecting the variety and the quality of the contents that can be accessed by Internet users? For the time being, the courts are still deliberating the FCC's decision, but some ISPs have already planned to introduce several discriminatory practices. For example, there are ISPs that intend to employ a bundling system, through which consumers wanting to access certain CPs (e.g. Facebook and Twitter) have to pay a premium social media package. Another practice that ISPs can adopt immediately is to exclude their own content from counting against their subscribers' data plan, thus modifying the consumers' choice. 
In this situation, you may wonder if there is any benefit for consumers and society to remove the NN rule. The answer of this question lies on the usual trade-off between static and dynamic efficiency. The FCC envisions that the shift from pre-emptive regulation to targeted enforcement based on actual market failure or anti-competitive conduct will boost ISPs' investments in Next Generations Access (NGA) networks. Such investments have been proven to promote productivity, employment and economic growth.

Now, let's go back to our article, which considers the possibility that ISPs can charge a termination fee to CPs to deliver their Internet traffic. First, we show that rival CPs have an incentive to reach a linking agreement that complements their contents when the termination fee set by the ISP is not too high, which is precisely what happens under the NN rule. The links to the rival's contents increase the quality of the service offered by each CP, and generate indirect traffic to them. Second, we explain that in the absence of the NN rule, the ISP may still be interested in setting a low termination fee to incentivize CPs to reach a linking agreement. The links generate more traffic, which translates into more termination revenues for the ISP. In addition, the increase in the quality of the contents generated by the links allows the ISP to set a higher subscription fee to the end users. It is only when the cost of increasing the network capacity is very high that the ISP would decide to increase the termination fee so as to disincentivize the use of links.

Taking this into account, we argue that when the ISP's transmission cost is sufficiently low and it sets a low termination fee, the imposition of NN is a sufficient, but not a necessary, condition to maximize social welfare. Indeed, social welfare could be maximized with the imposition of a positive price ceiling for the termination fee. When the transmission cost takes higher values, however, the welfare-maximizing and the profit-maximizing termination fees may not be aligned, and the regulation of the termination fee may be necessary. In this situation, the NN rule is less likely to be justifiable since it proves to be detrimental in most cases.

To sum up, Net Neutrality has been an essential regulation for the Internet and its relaxation can have important consequences which have not been fully examined yet. Our work has tried to contribute to the debate about this rule by analysing its effects on the linking activity of Content Providers. We have shown that the NN rule favours the use of links by CPs, although in some cases this regulation may lead to excessive indirect Internet traffic from a social perspective.

Notes:

- This blog post is based on the authors' paper Net Neutrality in a hyperlinked Internet economy, International Journal of Industrial Organization.

- The post gives the views of its authors, not the position of the institutions they represent, The LSE Business Review or the London School of Economics.

- Featured image credit: image by Mikes, via Pexels.

- When you leave a comment, you're agreeing to our Comment Policy.

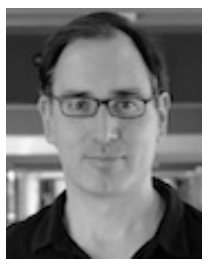

Joan Calzada is associate professor of economics at the University of Barcelona. He holds an MSc in Economics from the University College of London and a PhD in Economics from the University of Barcelona. Moreover, he is the director of the MSc in Economics at the University of Barcelona. His research interests are the economic regulation of telecommunications, Internet and air transportation. Some of his recent papers study the liberalization of the telecommunication market, the universal service policies implemented in network industries and the prices of broadband services. His research has appeared in academic journals such as The Economic Journal, Marketing Science, International Journal of Industrial Organization, Journal of Regulatory Economics, Information Economics and Policy, and Telecommunications Policy. He has advised several bodies, including the European Commission, CMT, OSINERGMIN, and Senatel. 


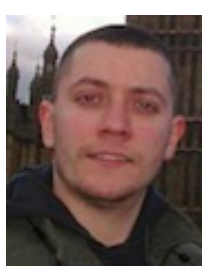

Markos Tselekounis is assistant professor of economics at the University of Piraeus. Before joining the University of Piraeus, he was a teaching assistant at the University of Athens and a postdoctoral research fellow at the NOVA University of Lisbon. His main research interests are in industrial economics, microeconomic theory, network economics and telecommunications policy. His research has appeared in many distinguished scientific international journals such as International Journal of Industrial Organization, Review of Industrial Organization and Journal of Regulatory Economics. He has been participating in several European and National projects in the area of network economics and regulation. Markos is also a member of the Adjunct Academic Staff of the Hellenic Open University and a Research Collaborator of the Center for Advanced Studies in Management and Economics (CEFAGE) of the University of Évora. 